\title{
11-year experience with Chest Wall resection and reconstruction for primary Chest Wall sarcomas
}

\author{
Ori Wald ${ }^{1 * \dagger}$, Idais Islam ${ }^{1 \dagger}$, Korach Amit ${ }^{1}$, Rudis Ehud ${ }^{1}$, Erez Eldad ${ }^{1}$, Or Omer ${ }^{2}$, Zik Aviad ${ }^{3}$, Shapira Oz. Moshe ${ }^{1}$ and \\ Izhar Uzi ${ }^{i^{*}}$
}

\begin{abstract}
Background \& Objectives: Primary chest wall sarcomas are rare and therapeutically challenging tumors. Herein we report the outcomes of a surgery-based multimodality therapy for these pathologies over an 11-year period. In addition, we present a case that illustrates the surgical challenges that extensive chest wall resection may pose.

Methods: Using the Society of Thoracic Surgeons general thoracic surgery database, we have prospectively collected data in our institute on all patients undergoing chest wall resection and reconstruction for primary chest wall sarcomas between June 2008-October 2019.

Results: We performed 28 surgical procedures on 25 patients aged 5 to 91 years (median age 33). Eleven tumors were bone- and cartilage-derived and 14 tumors originated from soft tissue elements. Seven patients $(7 / 25,28 \%)$ received neo-adjuvant therapy and 14 patients $(14 / 25,56 \%)$ received adjuvant therapy. The median number of ribs that were resected was 2.5 (range 0 to 6). In 18/28 (64\%) of surgeries, additional skeletal or visceral organs were removed, including: diaphragm [1], scapula [2], sternum [2], lung [2], vertebra [1], clavicle [1] and colon [1]. Chest wall reconstruction was deemed necessary in 16/28 (57\%) of cases, polytetrafluoroethylene (PTFE) Gore-Tex patches was used in 13/28 (46\%) of cases and biological flaps where used in 4/28 (14\%) of cases. R0, R1 and R2 resection margins were achieved in 19/28 (68\%), 9/28 (32\%) and 0/28 (0\%) of cases, respectively. The median follow up time was 33 months (range 2 to 138). During the study period, disease recurred in $8 / 25$ (32\%) of patients. Of these, 3 were re-operated on and are free of disease. At date of last follow up, 5/25 (20\%) of patients have died due to their disease and in contrast, 20/25 (80\%) were alive with no evidence of disease.

Conclusions: Surgery-based multimodality therapy is an effective treatment approach for primary chest wall sarcomas. Resection of additional skeletal or visceral organs and reconstruction with synthetic and/or biological flaps is often required in order to obtain RO resection margins. Ultimately, long-term survival in this clinical scenario is an achievable goal.
\end{abstract}

Keywords: Primary chest wall sarcoma, Chest wall resection, Chest wall reconstruction

\footnotetext{
* Correspondence: oriwald@hadassah.org.il; izharu@hadassah.org.il

${ }^{+}$Ori Wald and Idais Islam contributed equally to this work.

'Department of Cardiothoracic Surgery, Hadassah Hebrew University

Hospital, Jerusalem, Israel

Full list of author information is available at the end of the article
}

(C) The Author(s). 2020 Open Access This article is distributed under the terms of the Creative Commons Attribution 4.0 International License (http://creativecommons.org/licenses/by/4.0/), which permits unrestricted use, distribution, and reproduction in any medium, provided you give appropriate credit to the original author(s) and the source, provide a link to the Creative Commons license, and indicate if changes were made. The Creative Commons Public Domain Dedication waiver (http://creativecommons.org/publicdomain/zero/1.0/) applies to the data made available in this article, unless otherwise stated. 


\section{Introduction}

Primary chest wall tumors comprise 1 to $2 \%$ of all thoracic neoplasms. They are classified according to their tissue of origin (bone and cartilage vs. soft tissue) and according to their malignant potential (benign vs. malignant). Approximately $60 \%$ of primary chest wall tumors are malignant sarcomas, of these, about $55 \%$ arise from bone or cartilage and about $45 \%$ from soft tissue elements [1]. The clinical presentation of primary chest wall sarcomas is diverse. Indolent tumors slowly grow and are either incidentally diagnosed or present as a painless, palpable mass. In contrast, highly aggressive tumors present as a rapidly growing mass that may invade adjacent thoracic structures such as the lung, mediastinum, vertebra and diaphragm. Consequently, aggressive chest wall sarcomas, often induce pain, shortness of breath, and in some cases, also systemic symptoms [1, 3]. The foundation of treatment for chest wall sarcomas is complete surgical resection to achieve surgical clear margins - R0. In advanced cases, chemotherapy and radiation are utilized either as neo-adjuvant treatments aiming to downstage the tumor and permit resection or as adjuvant treatments aiming to prevent local and systemic recurrence. Metastatic disease is generally considered a contraindication for surgery [2, 4-7]. Given the rare occurrence of primary chest wall sarcomas only a limited number of publications have been published on the long-term outcomes of surgery in this clinical scenario. To expand the available data in this field, we herein report our 11-year experience with chest wall resection and reconstruction for primary chest wall sarcomas.

\section{Material and methods}

\section{Data collection}

Using our departmental prospectively maintained Society of Thoracic Surgeons (STS) database, we identified 25 patients that were operated by a single surgical team (UI, OW) for primary chest wall sarcomas between June 2008 to October 2019. All patients had a confirmed pathological diagnosis. Data on the clinical characteristic and on the outcomes of these patients were prospectively collected and retrospectively reviewed. Complete follow up data was available for $100 \%$ of patients. A waiver for patient consent was obtained.

\section{Patient selection}

We performed surgery on patients who's tumors were considered completely resectable unless their general medical condition did not permit surgery. Metastatic disease was considered a contraindication for surgery. All cases were reviewed by a multidisciplinary team (MDT) prior to surgery. Neo-adjuvant chemotherapy was prescribed according to the MDT decision and adjuvant treatments (chemotherapy and radiation) were considered again by the MDT according to the primary diagnosis, the surgical outcomes and the final pathological report.

\section{Statistics}

Overall survival (OS) was defined as time from date of surgery to death of any cause. Disease free survival (DFS) was defined as time from date of surgery to date of disease recurrence as evident in follow up imaging. Patients were censored on day of last follow up (December 2019). OS is presented using Kaplan-Meier curves.

\section{Results}

\section{Patient characteristics, tumor histology and adjuvant therapeutics}

Between 6 and 2018 to 10-2019, twenty-five patients aged 5 to 91 years (median age 33, male to female ratio 16:9) were diagnosed with primary chest wall sarcomas amenable to surgical resection (Table 1). Eleven tumors (44\%) were bone- and cartilage-derived (6 Ewing sarcoma, 4 chondrosarcoma and 1 atypical ossifying fibromyxoid tumor) and 14 (56\%) tumors originated from soft tissue elements (5 desmoid, 2 synovial sarcoma, 2 pleomorphic sarcoma, 1 leiomyosarcoma, 1 fibromixoid sarcoma, 1 angiosarcoma, 1 liposarcoma and 1 epithelioid hengioendothelioma). Further, thirteen $(52 \%)$ of the tumors were low grade (5 desmoid tumors, 3 chondrosarcoma, 1 liposarcoma, 1 hemangioendothelioma, 1 leiomyosarcoma, 1 fibromixoid sarcoma and 1 atypical ossifying fibromyxoid tumor), Three (12\%) were intermediate grade (2 synovial sarcomas and 1 chondrosarcoma) and nine (36\%) were high grade (6 Ewing sarcoma, 2 pleomorphic sarcoma and 1 angiosarcoma). The median tumor size was $7 \mathrm{~cm}$ (range $3 \mathrm{~cm}$ to $21 \mathrm{~cm}$ ). Overall, seven patients $(28 \%)$ received neo-adjuvant chemotherapy and 14 patients (56\%) received adjuvant therapy. Neoadjuvant chemotherapy was given in six cases of Ewing sarcoma and one case of synovial sarcoma. No pre-operative radiation treatments were administered. With respect to adjuvant treatments, chemotherapy was given in four cases (16\%) (2 Ewing sarcoma, 1 pleomorphic sarcoma and 1 angiosarcoma), radiotherapy was given in four cases (16\%) (2 desmoid tumors, 1 synovial sarcoma and 1 Ewing sarcoma), chemotherapy and radiotherapy were given in four cases (16\%) (3 Ewing sarcoma and 1 fibromexoid sarcoma) and Tamoxifen was given in two cases $(8 \%)$ for recurrent desmoid tumors. Chemotherapy and radiation protocols were prescribed and administered by the oncology team after discussion in the MDT meeting. Particulate protocols were based on clinical practice guidelines [8].

\section{Operative procedure}

We performed a total of 28 surgical procedures on 25 patients. Antibiotics to cover skin microbiota were given for $24 \mathrm{~h}$ in the preoperative period regardless of the extent of resection and regardless of the intra-operative use of synthetic patches. The median number of ribs that were resected was 2.5 (range 0 to 6). Further, in 18/ $28(64 \%)$ of surgeries additional skeletal or visceral 
Table 1 This table summarizes the key clinical and histopathological characteristics of the study population. In addition, it summarizes the surgical and therapeutic interventions that each patient had. The table is organized first according to the grade of the tumors and next according to the histological type of the tumor. OS - Overall Survival; DFS - Disease Free Survival; Size - tumor size in centimeters

\begin{tabular}{|c|c|c|c|c|c|c|c|c|c|c|}
\hline Age & Sex & OS & DFS & Resection & Primary Dx & Size & Grade & Mode of Repair & Neoadjuvent & Adjuvent \\
\hline 64 & Female & 10 & 3 & R1 & Angiosarcoma & 15 & High & $\begin{array}{l}\text { GoreTex patch + } \\
\text { musculocutaneous flap }\end{array}$ & & $\begin{array}{l}\text { Chemotherapy + } \\
\text { Radiotherapy }\end{array}$ \\
\hline 16 & Male & 9 & 1 & Ro & Ewing sarcoma & 11 & High & $\begin{array}{l}\text { GoreTex patch + primary } \\
\text { repair }\end{array}$ & Chemotherapy & $\begin{array}{l}\text { Chemotherapy + } \\
\text { Radiotherapy }\end{array}$ \\
\hline 10 & Female & 28 & 27 & Ro & Ewing sarcoma & 8 & High & $\begin{array}{l}\text { GoreTex patch + primary } \\
\text { repair }\end{array}$ & Chemotherapy & $\begin{array}{l}\text { Chemotherapy + } \\
\text { Radiotherapy }\end{array}$ \\
\hline 31 & Male & 138 & 138 & Ro & Ewing sarcoma & 8 & High & $\begin{array}{l}\text { GoreTex patch + primary } \\
\text { repair }\end{array}$ & Chemotherapy & $\begin{array}{l}\text { Chemotherapy }+ \\
\text { Radiotherapy }\end{array}$ \\
\hline 12 & Female & 6 & 3 & R1 & Ewing sarcoma & 13 & High & $\begin{array}{l}\text { GoreTex patch + primary } \\
\text { repair }\end{array}$ & Chemotherapy & $\begin{array}{l}\text { Chemotherapy + } \\
\text { Radiotherapy }\end{array}$ \\
\hline 5 & Male & 13 & 13 & Ro & Ewing sarcoma & 6 & High & Primary repair & Chemotherapy & $\begin{array}{l}\text { Chemotherapy + } \\
\text { Radiotherapy }\end{array}$ \\
\hline 25 & Male & 10 & 10 & Ro & Ewing sarcoma & 20 & High & $\begin{array}{l}\text { GoreTex patch + primary } \\
\text { repair }\end{array}$ & Chemotherapy & Radiotherapy \\
\hline 91 & Female & 9 & 7 & R1 & Pleomorphic sarcoma & 14 & High & Primary repair & & Chemoterapy \\
\hline 67 & Female & 80 & 80 & Ro & Pleomorphic sarcoma & 9 & High & $\begin{array}{l}\text { Musculocutaneous skin } \\
\text { flaps }\end{array}$ & & \\
\hline 66 & Male & 2 & 2 & Ro & Chondrosarcoma & 3 & Intermediate & Primary repair & & \\
\hline 13 & Male & 27 & 27 & Ro & Synovial sarcoma & 3 & Intermediate & $\begin{array}{l}\text { GoreTex patch + primary } \\
\text { repair }\end{array}$ & & \\
\hline 18 & Male & 52 & 52 & Ro & Synovial sarcoma & 5 & Intermediate & Primary repair & Chemotherapy & Radiotherapy \\
\hline 66 & Male & 3 & 3 & Ro & $\begin{array}{l}\text { Atypical ossifying } \\
\text { fibromyxoid tumor }\end{array}$ & 9 & Low & Primary repair & & \\
\hline 55 & Male & 33 & 33 & Ro & Chondrosarcoma & 6 & Low & $\begin{array}{l}\text { GoreTex patch + primary } \\
\text { repair }\end{array}$ & & \\
\hline 57 & Male & 119 & 119 & $\mathrm{R} 1$ & Chondrosarcoma & 7 & Low & Primary repair & & \\
\hline 64 & Male & 107 & 107 & Ro & Chondrosarcoma & 8 & Low & $\begin{array}{l}\text { GoreTex patch + primary } \\
\text { repair }\end{array}$ & & \\
\hline \multirow[t]{2}{*}{$26^{a}$} & Female & 123 & 55 & $\mathrm{R} 1$ & Desmoid & 10 & Low & Primary repair & & Radiotherapy \\
\hline & & & & Ro & Desmoid & 6 & Low & Primary repair & & \\
\hline 25 & Male & 40 & 40 & Ro & Desmoid & 3 & Low & $\begin{array}{l}\text { GoreTex patch + primary } \\
\text { repair }\end{array}$ & & \\
\hline 64 & Female & 48 & 41 & R1 & Desmoid & 5 & Low & $\begin{array}{l}\text { GoreTex patch + primary } \\
\text { repair }\end{array}$ & & Tamoxifen \\
\hline \multirow[t]{2}{*}{$54^{a}$} & Male & 119 & 24 & $\mathrm{R} 1$ & Desmoid & 5 & Low & Primary repair & & Radiotherapy \\
\hline & & & & $\mathrm{R} 1$ & Desmoid & 6 & Low & Cutaneous skin flaps & & Tamoxifen \\
\hline \multirow[t]{2}{*}{$20^{a}$} & Female & 135 & 20 & RO & Desmoid & 7 & Low & Primary repair & & \\
\hline & & & & Ro & Desmoid & 4 & Low & Primary repair & & \\
\hline 22 & Female & 105 & 105 & Ro & $\begin{array}{l}\text { Epithelioid } \\
\text { hemangioendothelioma }\end{array}$ & 7 & Low & Primary repair & & \\
\hline 35 & Male & 33 & 33 & Ro & Fibromixoid sarcoma & 13 & Low & $\begin{array}{l}\text { GoreTex patch + primary } \\
\text { repair }\end{array}$ & & $\begin{array}{l}\text { Chemotherapy }+ \\
\text { Radiotherapy }\end{array}$ \\
\hline 69 & Male & 77 & 77 & Ro & Leiomyosarcoma & 6 & Low & $\begin{array}{l}\text { Musculocutaneous skin } \\
\text { flaps }\end{array}$ & & \\
\hline 71 & Male & 9 & 9 & R1 & Liposarcoma & 21 & Low & Primary repair & & \\
\hline
\end{tabular}

${ }^{a}$ These patients had a second operation for disease recurrence 
organs were removed, including: diaphragm (8), scapula (4), sternum (4), lung (4), vertebra (1), clavicle (1) and colon (1). In addition, in one case, complete dissection of the brachial plexus was performed to release it from an invading synovial sarcoma. Chest wall reconstruction was deemed necessary in 16/28 (57\%) of cases. In 13/28 (46\%) of cases PTFE Gore-Tex patches were used to reconstruct the skeletal gap in the chest wall and in addition, in $4 / 28$ of cases (14\%) rotational flaps were used to cover soft tissue gaps (including 2 latissimus dorsi musculocutaneous flaps, 1 rectus abdominis musculocutaneous flap and 1 rotated skin flap). In all other cases, the wound was primarily closed by skin and subcutaneous tissue flaps that were raised along the incision edge. We routinely inspected the skin incision edge and the biological flaps to confirm their viability (we performed physical examination rather than ultrasound doppler), and when we identified flap engorgement or venous bleeding from the tissue edge we used to irrigate and insufflate the tissue with heparin to permit further oozing and release of tension from the tissue. With respects to gaps in the diaphragm, we were able to primarily repair these gaps by circumferentially suturing of the free diaphragmatic edge to the inferior costal margin. Overall, R0, R1 and R2 resection margins were achieved in $19 / 28(68 \%), 9 / 28(32 \%)$ and $0 / 28(0 \%)$ of cases respectively.

\section{Short-term outcomes}

The post operative course was generally uneventful and all patients recovered well from surgery. Five (18\%) postoperative complication were recorded within the first 30 postoperative days including, two superficial wound infections, one case of cutaneous flap dehiscence requiring revision, one case of drainage of wound hematoma and one case of deep vein thrombosis. Resolution of these complications was complete in all patients. There was no operative or postoperative mortality.

\section{Long-term outcome}

We had a $100 \%$ follow up rate on our study population. The median follow up time was 33 months (range 2 to 138). During the study period the disease recurred in $8 /$ 25 (32\%) of patients. In particular, the disease recurred in three patients with desmoid tumors, three patients with Ewing sarcoma, one patient with angiosarcoma, and one patient with pleomorphic sarcoma. The median time for disease recurrence for desmoid tumors was 24 month (range 20 to 55 months) whereas the median time for disease recurrence in the other sarcomas was 3 months (range 1 to 27 months). Remarkably, the three patients with recurrent desmoid tumor were re-operated on and at date of last follow up, were free of disease. Furtther, at date of last follow up, 5/25 (20\%) of patients have died due to their disease (3 Ewing sarcoma 1 angiosarcoma, and 1 pleomorphic sarcoma) and in contrast, $20 / 25(80 \%)$ were alive with no evidence of disease. Thus, the overall three- and five-year survival rates were $80 \%$ (Fig. 1).

\section{Brief case presentation - extensive chest wall resection for angiosarcoma}

To illustrate the complexity and challenges involved in the surgical care of patient with chest wall sarcomas we present the case of a 64-year-old woman with a diagnosis of a high-grade angiosarcoma of the chest. In brief, this patient history is notable for a left breast cancer that was diagnosed in 2000. Initially, she underwent a lumpectomy with sentinel lymph node sampling that was negative. However, since the characteristics of her tumor were aggressive she thereafter received adjuvant chemotherapy, hormonal therapy (Tamoxifen) and radiation to the surgical site. Ten years later, she was diagnosed with an intermediate to high-grade angiosarcoma at the surgical site. She then had a formal mastectomy with wide local resection and on pathology the resection margins were clear. Consequently, no further treatments were given. A year later in 2011, she had reconstruction of her left breast using a latissimus dorsi musculocutaneous flap. Unfortunately, in 2017 a large mass involving the deep layers of her left chest wall was seen in follow up MRI - Fig. 2a. Biopsy revealed a high-grade angiosarcoma with MIB proliferation index $>50 \%$. The case was discussed in the MDT meeting where the oncologist and radiotherapists were skeptical about the option of shrinking her tumor with neo-adjuvant chemo-radiotherapy. We therefore offered an upfront salvage resection attempt.

To achieve complete resection we planed our resection margins to extend laterally towards the posterior axillary line and medially towards the center of the sternal bone, we planed to reconstruct the skeletal gap with a PTFE GoreTex patch - Fig. 2b (the resection margins - B1, the actual gap in the chest wall with exposure of the entire left lung B2, and the reconstruction phase with a PTFE Gore-Tex patch - B3 are shown). Further, given that during surgery we anticipated to resect the latissimus dorsi muscle flap and also to sacrifice the left internal mammy artery, we planed to reconstruct the chest wall with a rotated right rectus abdominis musculocutanous flap - Fig. 2b (the planed harvesting of the rectus abdominis musculocutaneous flap - B4, its transfer and anchorage at the primary surgical site - B5, and the closure of the abdominal site - B6 are shown). The surgical course was uneventful and our intra-operative assessment was that we performed the widest possible resection. We estimated that further extension of the resection may endanger the patient with complex wound healing complications. Overall the patient recovered 


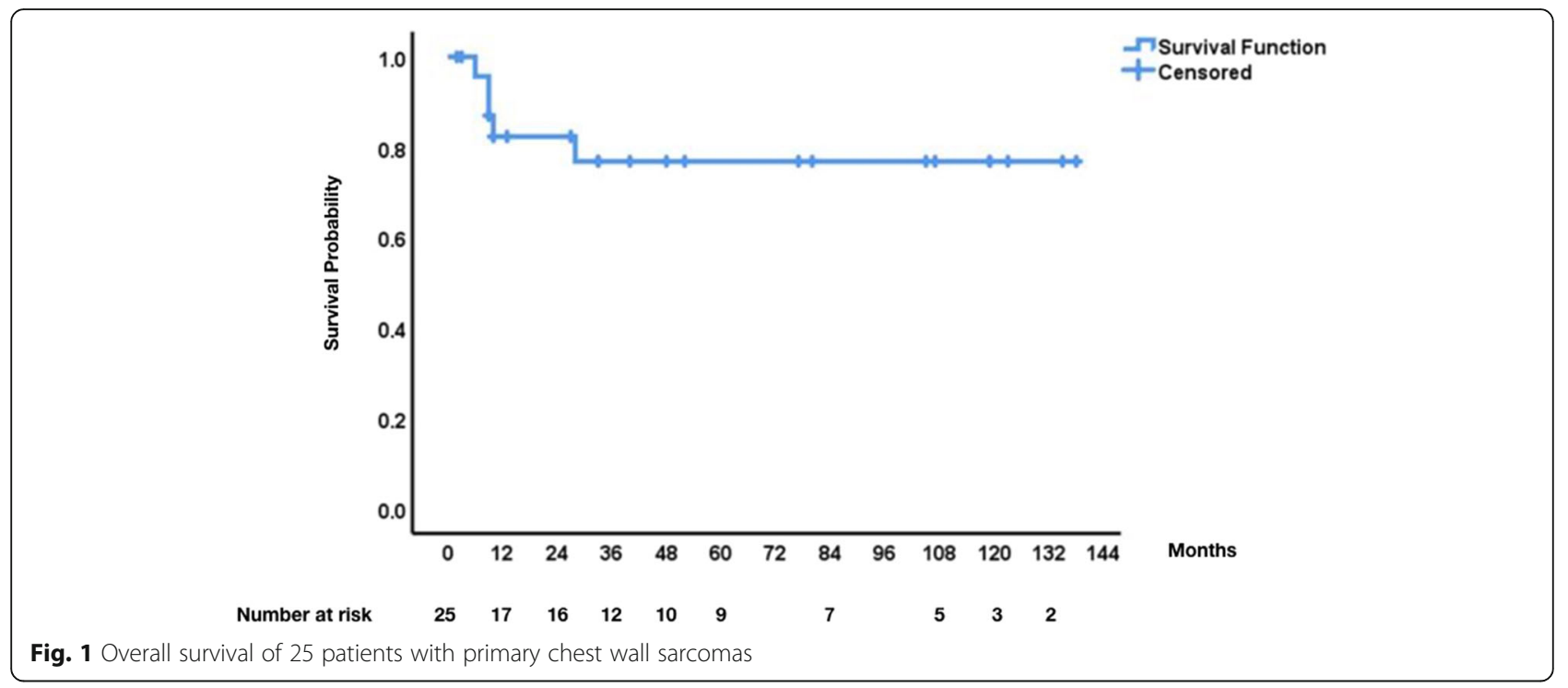

very well from surgery with no complications. On final pathology, the tumor size was $14.5 \mathrm{~cm}$ and the resection margins had microscopic islets of tumor at the lateral resection border - R1. Unfortunately the disease macroscopically recurred early thereafter (3 months) and the patients' overall survival from date of surgery was 10 months.

\section{Discussion}

The preliminary workup of a suspicious chest wall mass includes: 1) a computed tomography (CT) scan and or a magnetic resonance imaging (MRI) of the chest to characterize the lesion and delineate its extent within the thoracic cavity; 2) a core needle biopsy to obtain a diagnosis and ascertain the tumor grade; and 3) a total body CT scan or a positive emotion tomography - CT (PET-CT) scan to search for metastatic spread [1, 3, 9]. Once this evaluation is complete considerations regarding the resectability of the tumor and the need for neoadjuvant therapy are made. Important factors influencing the design of the treatment plan include tumor histology, grade and size, the potential to achieve clear surgical margins and the general health status of the patient [10-14]. Overall, we performed 28 surgeries on 25 patient. Seven young (age 5 to 31 ) and generally healthy patients received neo-adjuvant chemotherapy for high and intermediate grade tumors. They all tolerated the

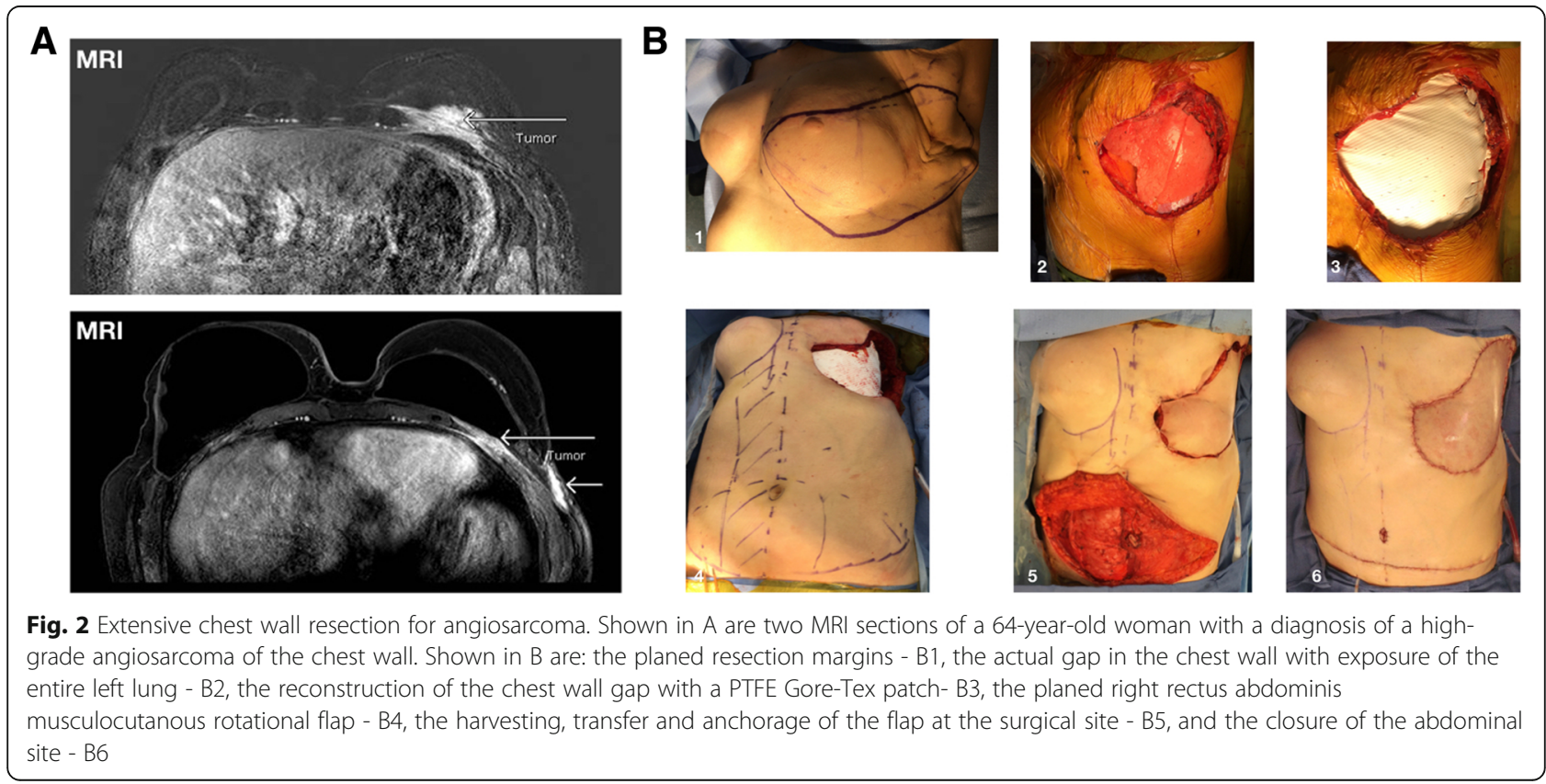


treatment well and in 6/7 (85\%) of their surgeries R0 margins were achieved. All of these patients also received adjuvant chemotherapy and or radiotherapy. In eighteen patients neo-adjuvant chemotherapy was not administered, either because they had low grade tumors (13 cases) or because their general health status did not permit ( 2 high grade cases) or because their tumors were considered small enough for upfront complete resection (1 high grade and 2 intermediate grade cases). Among the 18 patients who did not receive neo-adjuvant treatment, R0 margins were achieved in 13/21 (62\%) of surgeries. Adjuvant chemotherapy or radiotherapy was given to five patients and two additional patients received Tamoxifen for desmoid tumors. The overall R0 resection rate in our series was 19/28 (68\%). When retrospectively evaluating which preoperative parameters might have contributed to $\mathrm{R} 1$ resection margins, we identified the following: 1) tumors larger than $10 \mathrm{~cm}$ (R1 margins in $5 / 8$ of such tumors); 2 ) a diagnosis of a desmoid tumor (R1 margins in $4 / 8$ of surgeries for this pathology); 3) Tumor extension to vital anatomic structure such as abdominal aorta and vertebral body; and 4) Intra-operative identification of tumor extension towards a resection margin that, if further extended, may create an unbridgeable gap in the chest wall (see case presentation).

Keeping in mind that achieving clear resection margins remains the key goal of surgery for chest wall sarcomas, we argue that it is important in the preoperative planning to thoroughly consider the desired extent of resection, and also to prepare for the appropriate reconstructive steps [2, $4-7,10-14]$. Overall, in the current series, we have applied an aggressive surgical resection approach. This is evident from the resection of additional skeletal or visceral organs in $64 \%$ of cases and from the necessity to reconstruct the chest wall in 57\% of cases. And yet, in some instances, the extent of the disease beyond the borders delineated in preoperative imaging was only revealed at time of surgery. In such scenarios, the decision of whether to extend the resection or not is made by the surgical team based on histological examination of snap frozen tissue samples obtained from the resection margins and on the surgeons' assessment of the consequences of extending the resection (i.e endangering vital organs, chances for surgical site healing complications and functional and cosmetic disability associated with extending the resection) [9]. The decision is often not easy to make and there is no substitute for the experience and expertise of the operating team.

The current report has several limitations, but also certain strengths. In particular, the overall small number of cases that we report on, makes any generalization of our observation difficult. In addition, the histological spectrum of pathologies that we report on is wide and includes both aggressive and indolent tumors. Furthermore, the follow up time on some of the patients is rather short and their age range is wide. Nevertheless, we argue that given the rarity of primary chest wall sarcomas, it is important to report even on a small and diverse number of cases, making the data available for future meta-analyses. Moreover, we consider our data strong with respect to its prospective method of data collection and the $100 \%$ follow up that we have on our study population. Finally, given that a single surgical team performed all surgeries the unity in surgical skills and judgment is assured throughout the study.

\section{Conclusion}

In conclusion, a multidisciplinary team of physicians is involved in the evaluation and management of primary chest wall sarcomas. Surgery-based multimodality therapy to achieve and maintain clear resection margins is the foundation of treatment for these pathologies. Longterm survival can be achieved in a significant portion of patients.

\section{Abbreviations}

CT: Computed tomography; DFS: Disease free survival; MDT: Multidisciplinary team; MRI: Magnetic resonance imaging; OS: Overall survival; PET-CT: Positive emotion tomography - CT; PTFE: Polytetrafluoroethylene; STS: Society of thoracic surgeons

Acknowledgments

There are no acknowledgements.

Authors' contributions

OW, II and IW - conceived and wrote the manuscript. KA, RE, EE, OO, ZA and SOM reviewed the manuscript and assisted in collecting the data.

\section{Funding}

This study is not funded.

Availability of data and materials

All the data for this study is available and provided in the Table 1.

Ethics approval and consent to participate

A waiver for patient consent was obtained.

Consent for publication

Subject to acceptance, authors will transfer copyright to the publisher.

Competing interests

The authors have no competing interests.

\section{Author details}

${ }^{1}$ Department of Cardiothoracic Surgery, Hadassah Hebrew University Hospital, Jerusalem, Israel. ${ }^{2}$ Department of Orthopedics, Hadassah Hebrew University Hospital, Jerusalem, Israel. ${ }^{3}$ Department of Oncology, Hadassah Hebrew University Hospital, Jerusalem, Israel.

Received: 19 October 2019 Accepted: 3 January 2020

Published online: 28 January 2020

References

1. Cipriano A, Burfeind W Jr. Management of Primary Soft Tissue Tumors of the Chest Wall. Thorac Surg Clin. 2017;27:139-47.

2. Athanassiadi K, Kalavrouziotis G, Rondogianni D, Loutsidis A, Hatzimichalis A, Bellenis I. Primary chest wall tumors: early and long-term results of surgical treatment. Eur J Cardiothorac Surg. 2001;19:589-93.

3. Thomas M, Shen KR. Primary tumors of the osseous Chest Wall and their management. Thorac Surg Clin. 2017;27:181-93. 
4. Abdel Rahman ARM, Rahouma M, Gaafar R, et al. Contributing factors to the outcome of primary malignant chest wall tumors. J Thorac Dis. 2017;9: 5184-93.

5. Bagheri R, Haghi SZ, Kalantari MR, et al. Primary malignant chest wall tumors: analysis of 40 patients. J Cardiothorac Surg. 2014;9:106.

6. Walsh GL, Davis BM, Swisher SG, et al. A single-institutional, multidisciplinary approach to primary sarcomas involving the chest wall requiring fullthickness resections. J Thorac Cardiovasc Surg. 2001;121:48-60.

7. Yoon SH, Jung JC, Park IK, Park S, Kang CH, Kim YT. Clinical outcomes of surgical treatment for primary Chest Wall soft tissue sarcoma. Korean J Thorac Cardiovasc Surg. 2019;52:148-54.

8. Seitz G, Urla C, Sparber-Sauer M, et al. Treatment and outcome of patients with thoracic tumors of the Ewing sarcoma family: A report from the Cooperative Weichteilsarkom Studiengruppe CWS-81, -86, -91, -96, and -2002P trials. Pediatr Blood Cancer. 2019;66(Suppl 3):e27884.

9. Raz DJ, Clancy SL, Erhunmwunsee LJ. Surgical Management of the Radiated Chest Wall and its Complications. Thorac Surg Clin. 2017;27:171-9.

10. McMillan RR, Sima CS, Moraco NH, Rusch WW, Huang J. Recurrence patterns after resection of soft tissue sarcomas of the chest wall. Ann Thorac Surg. 2013;96:1223-8

11. Sabanathan $S$, Shah R, Mearns AJ. Surgical treatment of primary malignant chest wall tumours. Eur J Cardiothorac Surg. 1997;11:1011-6.

12. Shewale JB, Mitchell KG, Nelson DB, et al. Predictors of survival after resection of primary sarcomas of the chest wall-a large, single-institution series. J Surg Oncol. 2018;118:518-24.

13. Tsukushi S, Nishida Y, Sugiura H, Nakashima H, Ishiguro N. Soft tissue sarcomas of the chest wall. J Thorac Oncol. 2009;4:834-7.

14. Unal OU, Oztop I, Yasar N, et al. Clinicopathologic characteristics, treatment outcomes, and prognostic factors of primary thoracic soft tissue sarcoma: a multicenter study of the Anatolian Society of Medical Oncology (ASMO). Thorac Cancer. 2015;6:85-90.

\section{Publisher's Note}

Springer Nature remains neutral with regard to jurisdictional claims in published maps and institutional affiliations.

Ready to submit your research? Choose BMC and benefit from:

- fast, convenient online submission

- thorough peer review by experienced researchers in your field

- rapid publication on acceptance

- support for research data, including large and complex data types

- gold Open Access which fosters wider collaboration and increased citations

- maximum visibility for your research: over $100 \mathrm{M}$ website views per year

At $\mathrm{BMC}$, research is always in progress.

Learn more biomedcentral.com/submissions 